\title{
Introduction to the Catalytic Combustion of Diesel Soot
}

Jian Liu, Zhen Zhao* and Chunming $\mathrm{Xu}^{*}$

State Key Laboratory of Heavy Oil, College of Science, China University of Petroleum, Beijing, 102249, P.R. China

The heterogeneous catalytic reaction containing solid particle as reactant is a class of important and complex chemical reaction. The solid particles such as soot emitted from diesel engines, are becoming increasingly important in the context of cleaning air and lowering automotive emissions. Diesel soot particulates are defined by the US Environmental Protection Agency (EPA) as "all compound collected on a pre-condition filter in diluted diesel exhaust gases at a maximum temperature of $50^{\circ} \mathrm{C}$ ". The catalytic combustion is considered as one of effective method for purifying these diesel soot pollutants. Supported oxide catalysts were originally developed for the catalytic combustion, but they are not especially active at low temperatures $\left(<400^{\circ} \mathrm{C}\right)$ under the loose contact condition between catalysts and soot $[1,2]$. Noble metal catalysts such as platinum and gold, on the other hand, are efficient and exhibits high activity [3,4]. However, Pt is very expensive and causes the great emissions of sulfates. Thus, the development of active and stable catalysts without noble metals for the catalytic combustion of soot particles at low-temperature remains a significant challenge.

Many other attempts have been made to develop catalyst for diesel soot combustion on the basis of simple metal oxides and mixed oxides. As we consider the results of this study, two challenges remain for future research, i.e., to design appropriate catalytic materials that possess strong redox ability and to design new systems that improve the contact between solid particles and catalyst. On the one hand, The catalysis nature of solid particle combustion is a deep oxidation process. Therefore, the redox property of the catalyst determines its' intrinsic activity. Some ideas should be considered to get high redox property. One is to select the transition metal elements, whose ions have several oxidation states and possess good redox properties such as, $\mathrm{Mn}, \mathrm{Co}, \mathrm{Fe}$ etc. The other one is to tune the redox property of complex oxides with the alkali metal or alkali earth metal ions.

On the other hand, the reactions of diesel soot oxidation is threephase catalyzing reactions. The reaction supposedly takes place at the three-phase boundary among a solid catalyst, a solid reactant (soot) and gaseous reactants $\left(\mathrm{O}_{2}, \mathrm{NO}\right)$. The efficiency of a catalyst is strongly influenced by the contact between solid particles and catalyst. Though by using many other mechanical methods, such as ball milling, mechanic mixing, part of the catalyst particles may be contacted with soot particle materials, this method gave only tight contact condition between soot and catalyst. The condition cannot be easily obtained under the real exhaust gases emitted from diesel engine. Therefore, the catalytic effect is weakened in the real application. Some strategies have been proposed for getting the good contact between the catalyst and soot $[5,6]$ :

a) To seek the oxides or mixed oxides with low melting points or low eutectic melting points. Molten salt catalysts under realistic conditions give promising results due to their active components with high mobility.

b) To synthesize nano-particle oxide catalyst. Since the nanoparticle catalysts have higher fraction of surface atoms than the conventional catalysts with large particle size, the catalyst is in close proximity with solid particles and more catalyst surface is exposed to reaction atmosphere. A decrease in particle size from $1 \mu \mathrm{m}$ to $10 \mathrm{~nm}$ will increase the probability of contact each other by 100 times. For a given catalyst, the more the surface of catalyst is exposed to solid particles, the stronger the catalytic effect. Therefore, the catalytic effect of nano-particle catalyst will be stronger than that of the big particles when the same amount of catalysts is used.

Similarly to noble metal Pt catalysts, to search the efficient oxide catalysts for catalyzing the $\mathrm{NO}$ to $\mathrm{NO}_{2}$. A strategy successfully developed by Johnson Matthey for their DPF is to use the oxidizing properties of $\mathrm{NO}_{2}$ to combust the soot particulates (PM), i.e. the famous CRT technology (continuous regeneration traps) ${ }^{7}$. In the CRT system the removal of $\mathrm{PM}$ by oxidation with $\mathrm{NO}_{2}$ is achieved by placing an Pt-based oxidation catalyst upstream of the trap in order to convert $\mathrm{NO}$ in the exhaust into $\mathrm{NO}_{2}$. The oxidizing ability of $\mathrm{NO}_{2}$ is much stronger than that of $\mathrm{O}_{2}$ and it can directly oxidize the soot particle to $\mathrm{CO}_{2}$. If the cheap metal oxide catalysts might oxidize $\mathrm{NO}$ to $\mathrm{NO}_{2}$ like Pt catalyst they could subtly change solid (soot) -solid (catalyst) contact into solid (soot) - gas $\left(\mathrm{NO}_{2}\right)$ - solid (catalyst) contact. Then, the catalyst should have good activity for oxidizing soot to $\mathrm{CO}_{2}$ and $\mathrm{CO}$ under loose contact conditions.

It is noted that the pore size of catalyst would affect the catalytic combustion of solid particles. The pore sizes of normal catalysts are less than $10 \mathrm{~nm}$, therefore, big soot particles are difficult to enter inner pores of the conventional catalysts. Thus, the contact area and the exposed active site amounts are limited and only the outer surface area is the valid reactive surface area for the title reactions. And then the catalytic performances of catalysts would be largely affected. Three-dimensionally ordered macroporous (3DOM) materials with big pore size $(>50 \mathrm{~nm})$ can permit solid reactant to enter the inner pores of materials and to easily transport and diffuse. Therefore, the tangible active points between reactant and catalysts will be increased dramatically.

In the end, the catalysts to be the used in the combustion of soot particles must be stable both at high temperatures. In any case, the catalyst stability is a key factor in determining its applicability in a commercial scale. Another key factors to be taken into account is

*Corresponding authors: Zhen Zhao, State Key Laboratory of Heavy Oil, College of Science, China, University of Petroleum, Beijing, 102249, P.R. China, E-mail: zhenzhao@cup.edu.cn

Chunming Xu, State Key Laboratory of Heavy Oil, College of Science, China, University of Petroleum, Beijing, 102249, P.R. China, E-mail: xcm@cup.edu.cn

Received August 18, 2011; Accepted November 14, 2011; Published November 16, 2011

Citation: Liu J, Zhao Z, Xu C (2011) Introduction to the Catalytic Combustion of Diesel Soot. J Pet Environ Biotechnol 2:e102. doi:10.4172/2157-7463.1000e102

Copyright: @ 2011 Liu J, et al. This is an open-access article distributed under the terms of the Creative Commons Attribution License, which permits unrestricted use, distribution, and reproduction in any medium, provided the original author and source are credited. 
Citation: Liu J, Zhao Z, Xu C (2011) Introduction to the Catalytic Combustion of Diesel Soot. J Pet Environ Biotechnol 2:e102. doi:10.4172/2157$7463.1000 \mathrm{e} 102$

Page 2 of 2

the presence of other gaseous products that may affect the catalytic behavior. In the case of diesel exhaust, the presence of $\mathrm{CO}_{2}, \mathrm{NO}_{2}$, and water is unavoidable, and in the majority of cases, $\mathrm{SO}_{2}$ is also important.

\section{References}

1. Krishna K, Bueno-López A, Makkee M, Moulijn JA (2007) Appl Catal B 75: 189-195.

2. Liu J, Zhao Z, Xu C, Duan A, Jiang G (2010) Ind Eng Chem Res 49: 3112-3119.
3. Oi-Uchisawa J, Obuchi A, Ohi A, Nanba T, Nakayama N(2008) Powder Technol 180: 39-44.

4. Wei Y, Liu J, Zhao Z, Chen Y, Xu C, et al. (2011) Angew Chem Int Ed 50: 23262329.Russo N, Furfori S, Fino D, Saracco G, Specchia V (2008) Appl Catal B 83: 85-95.

5. Sophie A. Cottilard (editor) 2011 Catalytic Combustion. Chapter 2: The Combustion of Soot. Nova Science Publishers, Inc: $1-29$.

6. Burch R (2004) Catal Rev 46: 271-334. 